\title{
Asymptotic properties of solutions of third-order nonlinear dynamic equations on time scales
}

\author{
S. H. Saker ${ }^{a, *}$, H. Hassan ${ }^{b}$ \\ ${ }^{a}$ Department of Mathematics, Faculty of Science, Mansoura University, Mansoura, Egypt. \\ ${ }^{b}$ Department of Mathematics, Faculty of Science, New Mansoura University, New Mansoura City, Egypt.
}

\begin{abstract}
This paper is concerned with the asymptotic properties of solutions of third-order nonlinear dynamic equations on time scales. Some sufficient conditions for oscillation and nonoscillation of solutions as well as the boundedness of the solutions are established.
\end{abstract}

Keywords: Oscillation, nonoscillation, boundedness, third-order dynamic equations, time scales.

2020 MSC: 34K11, 34N05, 34C10, 39A21, 39A43, 26E70.

(C)2022 All rights reserved.

\section{Introduction}

The study of dynamic equations on time scales, which goes back to its founder Stefan Hilger [21], is an area of mathematics that has recently received a lot of attention. It has been created in order to unify the study of differential and difference equations. The general idea is to prove a result for dynamic equations where the domain of the unknown function is a so-called time scale, which is an arbitrary closed subset of the reals. The three most popular examples of calculus on time scales are differential calculus when $\mathbb{T}=\mathbb{R}$, difference calculus when $\mathbb{T}=\mathbb{N}$, and quantum calculus (see Kac and Cheung [22]), when $\mathbb{T}=q^{\mathbb{N}_{0}}=\left\{q^{t}: t \in \mathbb{N}_{0}\right\}$, where $q>1$. Since then several authors have expounded on various aspects of this new theory, see the survey paper by Agarwal, Bohner, O'Regan, and Peterson [4] of time scales calculus, and the references cited therein. For more details, we refer the reader to the books by Bohner and Peterson $[9,10]$ which summarize and organize much of time scale calculus.

In recent years, there has been a great interest in studying the oscillation and nonoscillation of solutions of dynamic equations on time scales. For example, in the papers $[5,7,8,11,12]$ the authors studied the oscillation of second order dynamic equations by employing the Riccati technique or the generalized Riccati technique, the reduction of orders and algebraic inequalities. The main idea is to establish sufficient conditions for oscillation depending on the coefficients of the equations and some external functions to obtain the sharp results of oscillation of solutions. For more details, of oscillation of second order

\footnotetext{
*Corresponding author

Email addresses: shsaker@mans.edu.eg (S. H. Saker), samir_saker@nmu.edu.eg (H. Hassan)

doi: $10.22436 /$ jmcs.026.03.05
}

Received: 2021-08-07 Revised: 2021-08-31 Accepted: 2021-09-30 
dynamic equations, we refer the reader to the book [27]. Dynamic equations (differential and difference equations) play an important role in modelling virtually every physical, technical, biological, ecological, and epidemiological process, from celestial motion, to bridge design, to interactions between neurons, to interaction between species, to spread of diseases with a population, etc. On the other hand, but not less important, PDEs are as well largely employed in modeling dynamical systems, and in this context non-oscillatory effects are often enforced by external sources and/or by (linear/nonlinear) high diffusion actions. These actions have smoothing and/or balancing influences in the model, so contrasting possible instabilities. For instance, we refer the reader to the papers [17, 18, 25] for models from mathematical biology, formulated by PDEs, where non-oscillatory phenomena are enforced by different smoothing actions.

The study of second-order dynamic equations has been extensively studied, whereas the study of third-order differential equations and third-order dynamic equations on time scales has not been studied extensively due to the challenges in determining the signs of the first and second derivatives of solutions of general differential equations (see $[2,13,24]$ and dynamic equations on time scales (see $[1,14-16,19$, 20, 26, 28-30])." and the references cited therein. In the following, we will present some of the results presented in some of these papers which explain the motivation of our paper. To the best of the authors' knowledge, the first paper that has been published for third order dynamic equations on time scales is the paper by Morelli and Peterson [26]. In this paper Morelli and Peterson studied the asymptotic behavior of solutions of third order dynamic equations of the form

$$
x^{\Delta \Delta \Delta}(\mathrm{t})+\mathrm{p}(\mathrm{t}) x^{\Delta}(\sigma(\mathrm{t}))+\mathrm{q}(\mathrm{t}) x(\sigma(\mathrm{t}))=0, \mathrm{t} \in\left[\mathrm{t}_{0}, \infty\right)_{\mathbb{T}}
$$

when $p(t) \leqslant 0$ and $q(t) \geqslant 0$, for $t \in\left[t_{0}, \infty\right)_{\mathbb{T}}$ where $\left[t_{0}, \infty\right)_{\mathbb{T}}$ is a time scale interval defined by $\left[t_{0}, \infty\right)_{\mathbb{T}}:=$ $\left[t_{0}, \infty\right) \cap \mathbb{T}$ with $t_{0} \in \mathbb{T}$. In particular, they proved that if $x(t)$ satisfies the conditions

$$
x\left(\sigma\left(t_{0}\right)\right) \geqslant 0, \quad x^{\Delta}\left(\sigma\left(t_{0}\right)\right)=0, \quad x^{\Delta \Delta}\left(t_{0}\right)>0,
$$

where $\sigma(t)$ is the forward jump operator (will be defined later), then

$$
x(t)>0, x^{\Delta}(t)<0, x^{\Delta \Delta}(t)>0, t \in\left(-\infty, \sigma\left(t_{0}\right)\right) .
$$

In 2005 Erbe, Peterson and Saker [14] applied the Riccati technique and established some sufficient conditions which guarantee that each solution of the equation

$$
\left(c(t)\left(\left(a(t) x^{\Delta}(t)\right)^{\Delta}\right)\right)^{\Delta}+q(t) f(x(t))=0, \quad t \in\left[t_{0}, \infty\right)_{\mathbb{T}},
$$

oscillates or satisfies $\lim _{t \rightarrow \infty} x(t)=0$. They obtained their results when $a(t), c(t)$, and $q(t)$ are positive real-valued rd-continuous functions and satisfy

$$
\int_{\mathrm{t}_{0}}^{\infty} \frac{1}{\mathrm{c}(\mathrm{t})}=\infty, \quad \int_{\mathrm{t}_{0}}^{\infty} \frac{1}{\mathrm{a}(\mathrm{t})}=\infty,
$$

and $f \in C(\mathbb{R}, \mathbb{R})$ satisfies $u f(u)>0$ and $f(u) / u \geqslant K>0$, for $u \neq 0$.

In 2006 Erbe, Peterson and Saker [15] studied the oscillation of third-order nonlinear dynamic equation of the form

$$
\left(\mathrm{c}(\mathrm{t})\left[\left(\mathrm{a}(\mathrm{t}) \mathrm{x}^{\Delta}(\mathrm{t})\right)^{\Delta}\right]^{\gamma}\right)^{\Delta}+\mathrm{f}(\mathrm{t}, \mathrm{x}(\mathrm{t}))=0, \quad \mathrm{t} \in\left[\mathrm{t}_{0}, \infty\right)_{\mathbb{T}},
$$

where $a(t)>0, c(t)>0$ are rd-continuous on $\mathbb{T}, \gamma \geqslant 1$ is a quotient of odd integers, and there exists a positive rd-continuous function $q$ such that $|f(t, u)| \geqslant q(t)\left|u^{\gamma}\right|$ and $u f(t, u)>0, u \neq 0$, and

$$
\int_{\mathrm{t}_{0}}^{\infty}\left(\frac{1}{\mathrm{c}(\mathrm{t})}\right)^{\frac{1}{\gamma}}=\infty, \quad \int_{\mathrm{t}_{0}}^{\infty} \frac{1}{\mathrm{a}(\mathrm{t})}=\infty .
$$


In 2007, Erbe et al. [16] extended the oscillation criteria of Hille and Nehari for second-order differential equations to the third-order linear dynamic equation

$$
x^{\Delta \Delta \Delta}(\mathrm{t})+\mathrm{q}(\mathrm{t}) x(\mathrm{t})=0, \mathrm{t} \in\left[\mathrm{t}_{0}, \infty\right)_{\mathbb{T}},
$$

where $q(t)$ is a positive real-valued rd-continous function, and proved that if $x(t)$ is a solution of $(1.1)$ and

$$
\int_{\mathrm{t}_{0}}^{\infty} \mathrm{q}(\mathrm{s}) \Delta \mathrm{s}=\infty
$$

then (1.1) has the property A, i.e., every solution $x(t)$ of $(1.1)$ is oscillatory or satisfies

$$
\lim _{t \rightarrow \infty} x(t)=\lim _{t \rightarrow \infty} x^{\Delta}(t)=\lim _{t \rightarrow \infty} x^{\Delta \Delta}(t)=0 .
$$

In $2009 \mathrm{Yu}$ and Wang [30] studied the asymptotic behavior of solutions of third-order nonlinear dynamic equations on time scales of the form

$$
\left(\frac{1}{a_{2}(t)}\left(\left[\frac{1}{a_{1}(t)}\left(x^{\Delta}(t)\right)^{\alpha_{1}}\right]^{\Delta}\right)^{\alpha_{2}}\right)^{\Delta}+q(t) f(x(t))=0, t \in\left[t_{0}, \infty\right)_{\mathbb{T}},
$$

where $f \in C(\mathbb{R}, \mathbb{R})$ satisfies $u f(u)>0$ and $f(u) / u \geqslant K>0$, for $u \neq 0$, or $f(u)>C>0, \alpha_{i}$ are quotients of odd positive integers, $i=1,2$, and $a_{1}(t), a_{2}(t)$ and $q(t)$ are positive rd-continuous functions and satisfy

$$
\int_{t_{0}}^{\infty} q(t) \Delta t=\infty, \quad \int_{t_{0}}^{\infty}\left(a_{i}(t)\right)^{\alpha_{i}} \Delta t=\infty, \quad \text { for } i=1,2
$$

Li et al. [23], Agarwal et al. [3], and Agarwal et al. [6] studied the oscillation behavior of the third-order nonlinear delay dynamic equation

$$
\left.\left[a(t)\left(r(t) x^{\Delta}(t)\right)^{\Delta}\right)^{\gamma}\right]^{\Delta}+f(t, x(\tau(t)))=0, t \in\left[t_{0}, \infty\right)_{\mathbb{T}},
$$

where $\gamma>0$ is a quotient of odd positive integers.

In 2012, Saker and Graef [28] extended the oscillation criteria of Hille and Nehari for second-order differential equations to the third order nonlinear neutral functional dynamic equation

$$
\left(p(t)\left[\left(r(t) x^{\Delta}(t)\right)^{\Delta}\right]^{\gamma}\right)^{\Delta}+f(t, y(\delta(t)))=0, \quad \text { for } t \in\left[t_{0}, \infty\right)_{\mathbb{T}}
$$

where $x(t):=y(t)+a(t) y(\tau(t)), \gamma>0$ is the quotient of odd positive integers, and $a, p, r, \tau$, and $\delta$ are positive rd-continuous function defined on $\mathbb{T}$. In 2012, Grace et al. [19] considered third-order neutral delay dynamic equation

$$
\left[r(t)(x(t)-a(t) x(\tau(t)))^{\Delta \Delta}\right]^{\Delta}+p(t) x^{\gamma}(\delta(t))=0, t \in\left[t_{0}, \infty\right)_{\mathbb{T}},
$$

and obtained several sufficient conditions for oscillation.

In 2014, Şenel and Utku [29] established some oscillation criteria for third-order neutral dynamic equations with distributed deviating arguments of the form

$$
\left[r(t)\left([x(t)+p(t) x(\tau(t))]^{\Delta \Delta}\right)^{\gamma}\right]^{\Delta}+\int_{c}^{d} f(t, x[\phi(t, \xi)]) \Delta \xi=0,
$$

where $\gamma>0$ is the quotient of odd positive integers with $r(t)$ and $p(t)$ real-valued rd-continuous positive functions.

Following this trend, in this paper, we will study the asymptotic behavior of solutions of nonlinear dynamic equations of third order of the form

$$
\left[a(t) x^{\Delta \Delta}(t)+p(t) x(t)\right]^{\Delta}+p(t) x^{\Delta}(t)+q(t) f\left(x^{\sigma}(t)\right)=0, \text { for } t \in\left[t_{0}, \infty\right)_{\mathbb{T}} .
$$

Throughout the paper, we suppose that the following assumptions hold: 
(i) $a, p, q \in C_{r d}\left(\left[t_{0}, \infty\right)_{\mathbb{T}},(0, \infty)\right.$;

(ii) $f \in C_{r d}(\mathbb{R}, \mathbb{R})$ with $u f(u)>0$ for $u \neq 0$;

(iii) $a^{\Delta}(t), a(t), p(t), q(t) \geqslant 0$ for $t \in\left[t_{0}, \infty\right)_{\mathbb{T}}$, and $\int_{t_{0}}^{\infty} \frac{1}{a(s)} \Delta s=\infty$.

By a solution of (1.2), we mean a function $x(t) \in \mathrm{C}_{r d}^{3}\left(\left[T_{x}, \infty\right)\right)$, for $T_{x} \geqslant t_{0}$, that satisfies (1.2) on $\left[T_{x}, \infty\right)$. We only consider the solutions $x(t)$ of (1.2) satisfying

$$
\sup \left\{|x(t)|: t \geqslant T_{x}\right\}>0, \text { for all } T_{x} \geqslant t_{0} .
$$

A solution $x$ of (1.2) is said to be oscillatory if it is neither eventually positive nor eventually negative, otherwise it is called nonoscillatory. Since we are interested in oscillatory behavior, we assume throughout that the given time scale $\mathbb{T}$ is unbounded above. We note that the equation (1.2) in its general form covers several different types of differential and difference equations depending on the choice of the time scale $\mathbb{T}$. For example, if $\mathbb{T}=\mathbb{R}$, then $\sigma(t)=t, \mu(t)=0, x^{\Delta}(t)=x^{\prime}(t), \int_{a}^{b} f(t) \Delta t=\int_{a}^{b} f(t) d t$, and (1.2) becomes the third-order nonlinear differential equation

$$
\left[a(t) x^{\prime \prime}(t)+p(t) x(t)\right]^{\prime}+p(t) x^{\prime}(t)+q(t) f(x(t))=0
$$

If $\mathbb{T}=\mathbb{N}$, then $\sigma(t)=t+1, \mu(t)=1, x^{\Delta}(t)=\Delta x(t)=x(t+1)-x(t), \int_{a}^{b} f(t) \Delta t=\sum_{t=a}^{b-1} f(t)$, and (1.2) becomes the third-order difference equation

$$
\Delta\left[\mathrm{a}(\mathrm{t}) \Delta^{2} x(\mathrm{t})+\mathrm{p}(\mathrm{t}) \mathrm{x}(\mathrm{t})\right]+\mathrm{p}(\mathrm{t}) \Delta x(\mathrm{t})+\mathrm{q}(\mathrm{t}) \mathrm{f}(\mathrm{x}(\mathrm{t}+1))=0 .
$$

If $\mathbb{T}=h \mathbb{Z}^{+}, h>0$, then $\sigma(t)=t+h, \mu(t)=h, x^{\Delta}(t)=\Delta_{h} x(t)=\frac{x(t+h)-x(t)}{h}$, and (1.2) becomes the third-order difference equation

$$
\Delta_{h}\left[a(t) \Delta_{h}^{2} x(t)+p(t) x(t)\right]+p(t) \Delta_{h} x(t)+q(t) f(x(t+h))=0 .
$$

The paper is organized as follows. In Section 2, we present some basic definitions concerning the calculus on time scales. In Section 3, we prove some basic lemmas and the main results in this paper.

\section{Preliminaries on time scales}

In this section, we present some preliminaries on time scales. For more details we refer the reader to the book [9, chaper 1]. A time scale $\mathbb{T}$ is an arbitrary nonempty closed subset of the real numbers $\mathbb{R}$. On $\mathbb{T}$ the forward and backward jump operators are defined by

$$
\sigma(t):=\inf \{s \in \mathbb{T}: s>t\}, \text { and } \rho(t):=\sup \{s \in \mathbb{T}: s<t\} .
$$

If $\sigma(t)>t$, we say that $t$ is right scattered, if $\rho(t)<t$, we say that $t$ is left scattered, if $t<\sup \mathbb{T}$ and $\sigma(t)=t$, we say that $t$ is right-dense and $t>\inf \mathbb{T}$ and $\rho(t)=t$, we say that $t$ is left-dense.

The graininess function $\mu(t)$ for a time scale $\mathbb{T}$ is defined by $\mu(t):=\sigma(t)-t$. A function $f:[a, b]_{\mathbb{T}} \rightarrow \mathbb{R}$ is said to be right-dense continuous if it is right continuous at each right-dense point and there exists a finite left limit at all left-dense points. The set of all such rd-continuous functions is denoted by $C_{r d}(\mathbb{T})$.

A function $p: \mathbb{T} \rightarrow \mathbb{R}$ is called positively regressive (we write $p \in \mathfrak{R}^{+}$) if it is rd-continuous function and satisfies $1+\mu(t) p(t)>0$ for all $t \in \mathbb{T}$. We define $f^{\Delta}(t)$ to be the number (provided it exists) with the property that for given any $\epsilon>0$ there is a neighborhood $U$ of $t$ with

$$
\left|[f(\sigma(t))-f(s)]-f^{\Delta}(t)[\sigma(t)-s]\right| \leqslant \epsilon|\sigma(t)-s|, \quad s \in U .
$$


In this case, we say that $f^{\Delta}(t)$ is the (delta) derivative of $f$ at $t$ and that $f$ is (delta) differentiable at $t \in \mathbb{T}^{k}$. If $f$ is (delta) differentiable at $t \in \mathbb{T}^{k}$, then $f^{\sigma}(t)=f(t)+\mu(t) f^{\Delta}(t)$. We will make use of the following product $f g$ and the quotient $f / g$ (where $g g^{\sigma} \neq 0$, where $g^{\sigma}=g \circ \sigma$ ) of two differentiable functions $f$ and $g$

$$
(f g)^{\Delta}=f^{\Delta} g+f^{\sigma} g^{\Delta}=f g^{\Delta}+f^{\Delta} g^{\sigma},\left(\frac{f}{g}\right)^{\Delta}=\frac{f^{\Delta} g-f g^{\Delta}}{g g^{\sigma}} .
$$

For $s, t \in \mathbb{T}$, a function $F: \mathbb{T} \rightarrow \mathbb{R}$ is called an antiderivative of $f: \mathbb{T} \rightarrow \mathbb{R}$ provided $F^{\Delta}=f(t)$ holds for all $t \in \mathbb{T}$. In this case we define the integral of $f$ by

$$
\int_{s}^{t} f(\tau) \Delta \tau=F(t)-F(s)
$$

For $s, t \in \mathbb{T}$, and a differentiable function $f$, the Cauchy integral of $\mathrm{f}^{\Delta}$ is defined by

$$
\int_{s}^{t} f(\tau) \Delta \tau=f(t)-f(s)
$$

and infinite integrals are defined as

$$
\int_{s}^{\infty} f(\tau) \Delta \tau=\lim _{t \rightarrow \infty} \int_{s}^{t} f(\tau) \Delta \tau
$$

An integration by parts formula reads

$$
\int_{s}^{t} f(\tau) g^{\Delta}(\tau) \Delta \tau=f(t) g(t)-f(s) g(s)-\int_{s}^{t} f^{\Delta}(\tau) g^{\sigma}(\tau) \Delta \tau
$$

For rd-continuous functions $f, g:[a, b] \rightarrow \mathbb{R}$, the Hölder inequality is given by

$$
\int_{a}^{b}|f(x) g(x)| \Delta x \leqslant\left\{\int_{a}^{b}|f(x)|^{p} \Delta x\right\}^{\frac{1}{p}}\left\{\int_{a}^{b}|g(x)|^{q} \Delta x\right\}^{\frac{1}{q}},
$$

where $p>1$ and $q=p /(p-1)$.

\section{Main results}

In this section, we prove the main results. We start by proving some basic lemmas.

Lemma 3.1. Assume that $\mathrm{g}(\mathrm{t})$ is an $r d$-continuous function defined on $\left[\mathrm{t}_{0}, \infty\right)_{\mathbb{T}}$. If

$$
\int_{\mathrm{t}_{0}}^{\infty} \mathrm{g}^{2}(\sigma(\mathrm{s})) \Delta \mathrm{s}<\infty, \text { and } \int_{\mathrm{t}_{0}}^{\infty}\left(\mathrm{g}^{\Delta \Delta}(\mathrm{s})\right)^{2} \Delta \mathrm{s}<\infty
$$

then

$$
\int_{\mathrm{t}_{0}}^{\infty}\left(\mathrm{g}^{\Delta}(\mathrm{s})\right)^{2} \Delta \mathrm{s}<\infty, \text { and } \int_{\mathrm{t}_{0}}^{\infty}\left(\mathrm{g}^{\Delta}(\sigma(\mathrm{s}))\right)^{2} \Delta \mathrm{s}<\infty .
$$

Proof. By employing Hölder's inequality, we see that

$$
\left(\int_{\mathrm{t}_{0}}^{\infty} \mathrm{g}^{\sigma}(\mathrm{s}) \mathrm{g}^{\Delta \Delta}(\mathrm{s}) \Delta \mathrm{s}\right)^{2} \leqslant\left(\int_{\mathrm{t}_{0}}^{\infty}\left|\mathrm{g}^{\sigma}(\mathrm{s})\right|^{2} \Delta \mathrm{s}\right)\left(\int_{\mathrm{t}_{0}}^{\infty}\left|g^{\Delta \Delta}(\mathrm{s})\right|^{2} \Delta \mathrm{s}\right) .
$$

That is,

$$
\left|\int_{\mathrm{t}_{0}}^{\infty} g^{\sigma}(s) g^{\Delta \Delta}(s) \Delta s\right|<\infty
$$


Now, we prove that (3.2) holds. Assume for the sake of contradiction that (3.2) does not hold, i.e., we assume that

$$
\int_{\mathfrak{t}_{0}}^{\mathrm{t}}\left(g^{\Delta}(s)\right)^{2} \Delta s=\infty, \text { and } \int_{\mathfrak{t}_{0}}^{\infty}\left(g^{\Delta}(\sigma(s))\right)^{2} \Delta s=\infty .
$$

Since

this implies that

$$
\int_{t_{0}}^{t}\left(g^{\Delta}(s)\right)^{2} \Delta s=g(t) g^{\Delta}(t)-g\left(t_{0}\right) g^{\Delta}\left(t_{0}\right)-\int_{t_{0}}^{t} g^{\sigma}(s) g^{\Delta \Delta}(s) \Delta s,
$$

$$
\lim _{t \rightarrow \infty} g(t) g^{\Delta}(t)=\infty
$$

As

$$
\left(g^{2}\right)^{\Delta}=\left(g+g^{\sigma}\right) g^{\Delta}, \text { and } g^{\sigma}(t)=g(t)+\mu(t) g^{\Delta}(t),
$$

we have that

$$
g^{2}(t)=2 \int_{t_{0}}^{t} g(s) g^{\Delta}(s) \Delta s+\int_{t_{0}}^{t} \mu(s)\left(g^{\Delta}(s)\right)^{2} \Delta s+g^{2}\left(t_{0}\right) \geqslant 2 \int_{t_{0}}^{t} g(s) g^{\Delta}(s) \Delta s+g^{2}\left(t_{0}\right) .
$$

Then by (3.3), we have that

$$
\lim _{t \rightarrow \infty} \int_{\mathfrak{t}_{0}}^{t} g^{2}(s) \Delta s=\infty
$$

and hence

$$
\lim _{t \rightarrow \infty} \int_{t_{0}}^{t}\left(g^{\sigma}(s)\right)^{2} \Delta s=\lim _{t \rightarrow \infty}\left\{\int_{t_{0}}^{t}\left[(g(s))^{2}+\left(\mu(s) g^{\Delta}(s)\right)^{2}+2 \mu(s) g(s) g^{\Delta}(s)\right] \Delta s\right\} .
$$

By combining (3.3) and (3.4), we obtain

$$
\int_{\mathrm{t}_{0}}^{\infty}\left(\mathrm{g}^{\Delta}(\sigma(\mathrm{s}))\right)^{2} \Delta \mathrm{s}=\infty
$$

which contradicts (3.1) and then (3.3) holds.

Lemma 3.2. Assume that (iii) holds. If $x(t)$ is a solution of (1.2), then

$$
F[x(t)]=a(t) x(t) x^{\Delta \Delta}(t)+p(t) x^{2}(t)-\frac{1}{2} a(t)\left(x^{\Delta}(t)\right)^{2},
$$

is nonincreasing on $\left[\mathrm{t}_{0}, \infty\right)_{\mathbb{T}}$.

Proof. From (3.5) and by using (iii), we see that

$$
\begin{aligned}
\mathrm{F}^{\Delta}[\mathrm{x}(\mathrm{t})]= & \mathrm{x}^{\sigma}(\mathrm{t})\left[\mathrm{a}(\mathrm{t}) \mathrm{x}^{\Delta \Delta}(\mathrm{t})+\mathrm{p}(\mathrm{t}) \mathrm{x}(\mathrm{t})\right]^{\Delta}+\mathrm{x}^{\Delta}(\mathrm{t})\left[\mathrm{a}(\mathrm{t}) \mathrm{x}^{\Delta \Delta}(\mathrm{t})+\mathrm{p}(\mathrm{t}) \mathrm{x}(\mathrm{t})\right] \\
& -\frac{1}{2} \mathrm{a}(\mathrm{t})\left[\mathrm{x}^{\Delta}(\mathrm{t})+\mathrm{x}^{\Delta}(\sigma(\mathrm{t}))\right] \mathrm{x}^{\Delta \Delta}(\mathrm{t})-\frac{1}{2} \mathrm{a}^{\Delta}(\mathrm{t})\left(\mathrm{x}^{\Delta}(\sigma(\mathrm{t}))\right)^{2} .
\end{aligned}
$$

Since $x^{\Delta}(\sigma(t))=x^{\Delta}(t)+\mu(t) x^{\Delta \Delta}(t)$, we obtain that

$$
\begin{aligned}
\mathrm{F}^{\Delta}[\mathrm{x}(\mathrm{t})]= & x^{\sigma}(\mathrm{t})\left[\mathrm{a}(\mathrm{t}) \mathrm{x}^{\Delta \Delta}(\mathrm{t})+\mathrm{p}(\mathrm{t}) \mathrm{x}(\mathrm{t})\right]^{\Delta}+\mathrm{a}(\mathrm{t}) \mathrm{x}^{\Delta}(\mathrm{t}) \mathrm{x}^{\Delta \Delta}(\mathrm{t})+\mathrm{p}(\mathrm{t}) \mathrm{x}(\mathrm{t}) \mathrm{x}^{\Delta}(\mathrm{t}) \\
& -\mathrm{a}(\mathrm{t}) \mathrm{x}^{\Delta}(\mathrm{t}) \mathrm{x}^{\Delta \Delta}(\mathrm{t})-\frac{1}{2} \mathrm{a}(\mathrm{t}) \mu(\mathrm{t})\left(\mathrm{x}^{\Delta \Delta}(\mathrm{t})\right)^{2}-\frac{1}{2} \mathrm{a}^{\Delta}(\mathrm{t})\left(\mathrm{x}^{\Delta}(\sigma(\mathrm{t}))\right)^{2} .
\end{aligned}
$$

As $x(\sigma(t))=x(t)+\mu(t) x^{\Delta}(t)$, we have that

$$
\mathrm{F}^{\Delta}[\mathrm{x}(\mathrm{t})]=\mathrm{x}^{\sigma}(\mathrm{t})\left[\mathrm{a}(\mathrm{t}) \mathrm{x}^{\Delta \Delta}(\mathrm{t})+\mathrm{p}(\mathrm{t}) \mathrm{x}(\mathrm{t})\right]^{\Delta}+\mathrm{p}(\mathrm{t}) x(\sigma(\mathrm{t})) \mathrm{x}^{\Delta}(\mathrm{t})
$$




$$
-p(t) \mu(t)\left(x^{\Delta}(t)\right)^{2}-\frac{1}{2} a(t) \mu(t)\left(x^{\Delta \Delta}(t)\right)^{2}-\frac{1}{2} a^{\Delta}(t)\left(x^{\Delta}(\sigma(t))\right)^{2} .
$$

Where $x(t)$ is a solution of (1.2), we obtain

$$
\left[\mathrm{a}(\mathrm{t}) \mathrm{x}^{\Delta \Delta}(\mathrm{t})+\mathrm{p}(\mathrm{t}) x(\mathrm{t})\right]^{\Delta}+\mathrm{p}(\mathrm{t}) \mathrm{x}^{\Delta}(\mathrm{t})=-\mathrm{q}(\mathrm{t}) \mathrm{x}^{\sigma}(\mathrm{t}) \mathrm{f}\left(\mathrm{x}^{\sigma}(\mathrm{t})\right)
$$

then

$$
F^{\Delta}[x(t)]=-q(t) x^{\sigma}(t) f\left(x^{\sigma}(t)\right)-p(t) \mu(t)\left(x^{\Delta}(t)\right)^{2}-\frac{1}{2} a(t) \mu(t)\left(x^{\Delta \Delta}(t)\right)^{2}-\frac{1}{2} a^{\Delta}(t)\left(x^{\Delta}(\sigma(t))\right)^{2} \leqslant 0,
$$

which implies that $F[x(t)]$ is nonincreasing on $\left[t_{0}, \infty\right)_{\mathbb{T}}$.

Lemma 3.3. Let $\mathrm{y}(\mathrm{t})$ be an $\mathrm{rd}$-continuous and $\Delta$ differentiable function on the interval $\left[\mathrm{t}_{0}, \infty\right]_{\mathbb{T}}$ such that $\mathrm{y}(\mathrm{t})>0$ for $\mathrm{t} \geqslant \mathrm{t}_{0}$. If

$$
\lim _{t \rightarrow \infty}\left(\frac{y^{\Delta}(t)}{y(t)}\right)=-\infty, \text { then } \lim _{t \rightarrow \infty} y(t)=0
$$

Proof. Since $y(t)>0$, for $t \geqslant t_{0}$, and

$$
\lim _{t \rightarrow \infty}\left(\frac{y^{\Delta}(t)}{y(t)}\right)=-\infty,
$$

we conclude that $y^{\Delta}(t)<0$ for $t \geqslant t_{0}$, and hence $\lim _{t \rightarrow \infty} y(t)$ exists and eventually decreasing. Suppose that

$$
\lim _{t \rightarrow \infty} y(t)=\lambda>0,
$$

and that there exists a real number $\delta<0$ satisfiying

$$
\frac{y^{\Delta}(t)}{y(t)}<\delta, \quad \text { on }\left[t_{1}, \infty\right)_{\mathbb{T}} \text { for some } t_{1}>t_{0} .
$$

Then

$$
y^{\Delta}(t)<\delta y(t), \text { for } t_{1}>t_{0}
$$

This implies that $y(t)<0$ for large $t$ which is contradiction.

Definition 3.4. Let $x(t)$ be a solution of (1.2) and define the set

$$
S=\left\{x(t): \lim _{t \rightarrow \infty} F[x(t)]=F_{0}>-\infty\right\} .
$$

We say that $x(t)$ belongs to the class $S_{I}$ if $F[x(t)] \geqslant 0$ on $\left[T_{1}, \infty\right)_{\mathbb{T}}$ for some $T_{1} \geqslant t_{0}$ and say that $x(t)$ belongs to the class $S_{\text {II }}$ if $F[x(T)]<0$ on $\left[T_{1}, \infty\right)_{\mathbb{T}}$ for some $T_{1} \geqslant t_{0}$.

We assume that the following conditions hold.

$\left(\mathrm{H}_{1}\right) \int_{\mathrm{t}_{0}}^{\infty} \mathrm{p}(\mathrm{s}) \Delta \mathrm{s}=\infty$.

$\left(\mathrm{H}_{2}\right)$ There exist constants $M>0$ and $\mathrm{N}>0$ such that

$$
M \leqslant \frac{f(u)}{u} \leqslant N, \quad \text { for all } u \neq 0 .
$$

$\left(\mathrm{H}_{3}\right)$ There exist constants $\mathrm{q}_{0}>0$ and $\mathrm{q}_{1}>0$ such that $\mathrm{q}_{0} \leqslant \mathrm{q}(\mathrm{t}) \leqslant \mathrm{q}_{1}$, for all $\mathrm{t} \geqslant \mathrm{t}_{0}$.

$\left(\mathrm{H}_{4}\right)$ There is a constant $\alpha$ such that $a^{\Delta}(t) \leqslant \alpha$, for all $t \geqslant t_{0}$.

$\left(H_{5}\right)$ There are constants $p_{0}, \delta$ such that $p(t) \geqslant p_{0}>0,\left|p^{\Delta}(t)\right| \leqslant \delta$ for all $t \geqslant t_{0}$.

$\left(\mathrm{H}_{6}\right) \mathrm{q}^{\Delta}(\mathrm{t}) \leqslant 0$. 
Theorem 3.5. Assume that $\left(\mathrm{H}_{1}\right)$ and $\left(\mathrm{H}_{2}\right)$ hold. If $x(\mathrm{t}) \in \mathrm{S}_{\mathrm{I}}$, then

$$
\int_{t_{0}}^{\infty}\left[\left(x^{\sigma}(t)\right)^{2}+\frac{\mu(s)}{M q_{0}}\left(p(s)\left(x^{\Delta}(s)\right)^{2}+\frac{1}{2} a(s)\left(x^{\Delta \Delta}(s)\right)^{2}\right)\right] \Delta s<\infty .
$$

Proof. We consider the case when $x(t)>0 t \geqslant t_{1}$. The proof of the case when $x(t)<0$ for $t \geqslant t_{1}$ is similar and will be omitted. By multiplying both sides of (1.2) by $x^{\sigma}(t)$, we see that

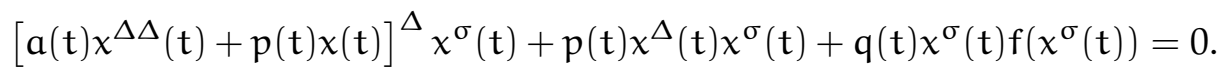

By integrating (3.7) from $t_{1}$ to $t$ we have that

$$
\begin{aligned}
& a(t) x^{\Delta \Delta}(t) x(t)+p(t) x^{2}(t)-a\left(t_{1}\right) x^{\Delta \Delta}\left(t_{1}\right) x\left(t_{1}\right)-p\left(t_{1}\right) x^{2}\left(t_{1}\right) \\
& \quad-\int_{t_{1}}^{t}\left[a(s) x^{\Delta \Delta}(s)+p(s) x(s)\right] x^{\Delta}(s) \Delta s+\int_{t_{1}}^{t} p(s) x^{\Delta}(s) x^{\sigma}(s) \Delta s+\int_{t_{1}}^{t} q(s) x^{\sigma}(s) f\left(x^{\sigma}(s)\right) \Delta s=0 .
\end{aligned}
$$

Since $x^{\sigma}(t)=x(t)+\mu(t) x^{\Delta}(t)$, then from (3.5) and (3.8), we see that

$$
\begin{aligned}
F & {[x(t)]-F\left[x\left(t_{1}\right)\right]+\frac{1}{2} a(t)\left(x^{\Delta}(t)\right)^{2}-\frac{1}{2} a\left(t_{1}\right)\left(x^{\Delta}\left(t_{1}\right)\right)^{2} } \\
& -\int_{t_{1}}^{t} a(s) x^{\Delta \Delta}(s) x^{\Delta}(s) \Delta s-\int_{t_{1}}^{t} p(s) x(s) x^{\Delta}(s) \Delta s+\int_{t_{1}}^{t} p(s) x(s) x^{\Delta}(s) \Delta s \\
& +\int_{t_{1}}^{t} \mu(s) p(s)\left(x^{\Delta}(s)\right)^{2} \Delta s+\int_{t_{1}}^{t} q(s) x^{\sigma}(s) f\left(x^{\sigma}(s)\right) \Delta s=0 .
\end{aligned}
$$

So, we have that

$$
\begin{aligned}
& \frac{1}{2} \int_{t_{1}}^{t} a^{\Delta}(s)\left(x^{\Delta}(\sigma(s))\right)^{2} \Delta s \\
& =\frac{1}{2} a(t)\left(x^{\Delta}(t)\right)^{2}-\frac{1}{2} a\left(t_{1}\right)\left(x^{\Delta}\left(t_{1}\right)\right)^{2}-\frac{1}{2} \int_{t_{1}}^{t} a(s) x^{\Delta \Delta}(s)\left(x^{\Delta}(s)+x^{\Delta}(\sigma(s))\right) \Delta s \\
& =\frac{1}{2} a(t)\left(x^{\Delta}(t)\right)^{2}-\frac{1}{2} a\left(t_{1}\right)\left(x^{\Delta}\left(t_{1}\right)\right)^{2}-\int_{t_{1}}^{t} a(s) x^{\Delta \Delta}(s) x^{\Delta}(s) \Delta s-\frac{1}{2} \int_{t_{1}}^{t} a(s) \mu(s)\left(x^{\Delta \Delta}(s)\right)^{2} \Delta s .
\end{aligned}
$$

Combining (3.9) and (3.10), we obtain

$$
\begin{aligned}
& F[x(t)]-F\left[x\left(t_{1}\right)\right]+\frac{1}{2} \int_{t_{1}}^{t} a^{\Delta}(s)\left(x^{\Delta}(\sigma(s))\right)^{2} \Delta s \\
& \quad+\frac{1}{2} \int_{t_{1}}^{t} a(s) \mu(s)\left(x^{\Delta \Delta}(s)\right)^{2} \Delta s+\int_{t_{1}}^{t} \mu(s) p(s)\left(x^{\Delta}(s)\right)^{2} \Delta s+\int_{t_{1}}^{t} q(s) x^{\sigma}(s) f\left(x^{\sigma}(s)\right) \Delta s=0 .
\end{aligned}
$$

Since $\left(H_{2}\right)$ and $\left(H_{3}\right)$ imply that $q(t) \chi^{\sigma}(t) f\left(x^{\sigma}(t)\right) \geqslant M q_{0}\left(x^{\sigma}(t)\right)^{2}$, then

$$
\begin{aligned}
& \int_{t_{1}}^{t}\left[\operatorname{Mq}_{0}\left(x^{\sigma}(t)\right)^{2}+\mu(s) p(s)\left(x^{\Delta}(s)\right)^{2}+\frac{1}{2} a(s) \mu(s)\left(x^{\Delta \Delta}(s)\right)^{2}\right] \Delta s \\
& \quad \leqslant F\left[x\left(t_{1}\right)\right]-F[x(t)]-\frac{1}{2} \int_{t_{1}}^{t} a^{\Delta}(s)\left(x^{\Delta}(\sigma(s))\right)^{2} \Delta s \leqslant F\left[x\left(t_{1}\right)\right]-F[x(t)] .
\end{aligned}
$$

So in view of Lemma 3.2 there is a positive constant $L_{1}$ such that

$$
\lim _{t \rightarrow \infty} \int_{t_{1}}^{t}\left[\left(x^{\sigma}(s)\right)^{2}+\frac{\mu(s) p(s)\left(x^{\Delta}(s)\right)^{2}}{M q_{0}}+\frac{a(s) \mu(s)\left(x^{\Delta \Delta}(s)\right)^{2}}{2 M q_{0}}\right] \Delta s \leqslant L_{1}<\infty .
$$


Remark 3.6. When $\mathbb{T}=\mathbb{R}$, then $\mu(t)=0$ and Theorem 3.5 reduces to Theorem 3.1 (i) in [20] by putting $\mathrm{b}(\mathrm{t})=0$.

Theorem 3.7. Assume that (iii) and $\left(\mathrm{H}_{1}\right)$ hold. If $x \in \mathrm{S}_{\mathrm{II}}$, then either $x(\mathrm{t})$ is oscillatory or satisfies $\lim _{\mathrm{t} \rightarrow \infty} x(\mathrm{t})=$ 0 .

Proof. Let $x(t)$ be a nonoscillatory solution of (1.2), and without loss of generality we assume that $x(t)>0$ for $t>t_{1}$ for some $t_{1} \geqslant t_{0}$. The proof of the case when $x(t)<0$ for $t>t_{1}$ is similar and will be omitted. Now, we prove that $\lim _{t \rightarrow \infty} x(t)=0$. Define for $T \geqslant t_{2}$,

$$
R_{T}(t)=\frac{x^{\Delta}(t)}{x(t)}+\int_{T}^{t} \frac{p(s) x(s)}{a(s) x^{\sigma}(s)} \Delta s
$$

Then

$$
\begin{aligned}
& \mathrm{R}_{\mathrm{T}}^{\Delta}(\mathrm{t})=\frac{\chi(\mathrm{t}) \chi^{\Delta \Delta}(\mathrm{t})-\left(\chi^{\Delta}(\mathrm{t})\right)^{2}}{\chi(\mathrm{t}) \chi^{\sigma}(\mathrm{t})}+\frac{\mathrm{p}(\mathrm{s}) \chi(\mathrm{s})}{\mathrm{a}(\mathrm{s}) \chi^{\sigma}(\mathrm{s})} \Delta \mathrm{s} \\
& =\frac{1}{a(t) x(t) x^{\sigma}(t)}\left(a(t) x(t) x^{\Delta \Delta}(t)-\frac{1}{2} a(t)\left[x^{\Delta}(t)\right]^{2}+p(t) x^{2}(t)\right)-\frac{\left(x^{\Delta}(t)\right)^{2}}{2 x(t) x^{\sigma}(t)} \\
& =\frac{\left[\mathrm{a}(\mathrm{t}) x(\mathrm{t}) \mathrm{x}^{\Delta \Delta}(\mathrm{t})-\frac{1}{2} \mathrm{a}(\mathrm{t})\left[\mathrm{x}^{\Delta}(\mathrm{t})\right]^{2}+\mathrm{p}(\mathrm{t}) \mathrm{x}^{2}(\mathrm{t})\right]}{\mathrm{a}(\mathrm{t}) \mathrm{x}(\mathrm{t}) \mathrm{x}^{\sigma}(\mathrm{t})}-\frac{\left(\mathrm{x}^{\Delta}(\mathrm{t})\right)^{2}}{2 x(\mathrm{t}) \mathrm{x}^{\sigma}(\mathrm{t})} \\
& =\frac{F[x(t)]}{a(t) x(t) x^{\sigma}(t)}-\frac{\left(x^{\Delta}(t)\right)^{2}}{2 x(t) x^{\sigma}(t)}<0 .
\end{aligned}
$$

From Lemma 3.2, since $F[x(t)]<0$ for $t \geqslant t_{2}$ for some $t_{2} \geqslant t_{1}$, then $R_{T}[t]$ is decreasing on $[T, \infty)_{T}$. Notice that if $T$ is chosen so that $x^{\Delta}(T)=0, R_{T}[T]=0$, and since $R_{T}^{\Delta}(t)<0$, we have $R_{T}[t]<0$ for all $t \geqslant T$. Together with the condition (iii) this implies

$$
\lim \frac{x^{\Delta}(t)}{x(t)}=-\infty
$$

By Lemma 3.3 we get that $\lim _{t \rightarrow \infty} x(t)=0$, which proves the theorem.

Corollary 3.8. Assume that (iii) and $\left(\mathrm{H}_{1}\right)$ hold. If $x(\mathrm{t})$ has a zero on $\left[\mathrm{t}_{1}, \infty\right)_{\mathbb{T}}$, then $\mathrm{x}(\mathrm{t})$ is either oscillatory or $\lim _{t \rightarrow \infty} x(t)=0$.

Proof. Assume that there exists a $t_{1}>t_{0}$, such that $x\left(t_{1}\right)=0$. This implies that

$$
\mathrm{F}\left[\mathrm{x}\left(\mathrm{t}_{1}\right)\right]=-\frac{1}{2} \mathrm{a}\left(\mathrm{t}_{1}\right)\left(\mathrm{x}^{\Delta}\left(\mathrm{t}_{1}\right)\right)^{2} \leqslant 0 .
$$

Then $x\left(t_{1}\right)$ belongs to Class $S_{I I}$, and the conclusion follows from Theorem 3.7.

Remark 3.9. Assume that and (iii), $\left(\mathrm{H}_{2}\right)$, and $\left(\mathrm{H}_{3}\right)$ hold. If $x(t)$ is a solution of (1.2) belonging to either Class $S_{I}$ or Class $S_{I I}$, then

$$
\int_{T}^{t}\left[\left(x^{\sigma}(s)\right)^{2}+\frac{\mu(s) p(s)\left(x^{\Delta}(s)\right)^{2}}{M q_{0}}+\frac{a(s) \mu(s)\left(x^{\Delta \Delta}(s)\right)^{2}}{2 M q_{0}}\right] \Delta s<\infty .
$$

Now from (3.6) and (3.11), we see that

$$
\int_{T}^{t}\left[\left(x^{\sigma}(s)\right)^{2}+\frac{1}{M q_{0}}\left(\mu(s) p(s)\left(x^{\Delta}(s)\right)^{2}+\frac{1}{2} a(s) \mu(s)\left(x^{\Delta \Delta}(s)\right)^{2}\right)\right] \Delta s<\frac{-F_{0}+F\left[x\left(t_{1}\right)\right]}{M q_{0}} \leqslant \frac{F\left[x\left(t_{1}\right)\right]-F_{0}}{M q_{0}}<\infty .
$$


Theorem 3.10. Assume that (iii) and $\left(\mathrm{H}_{4}\right)$ hold. If $x \in \mathrm{S}_{\mathrm{II}}$, then

$$
\int_{T}^{t}\left(a^{\sigma}(s)\left(\chi^{\Delta}(s)\right)^{2}+\frac{1}{2} \mu(s)[a(s) \chi(s)]^{\Delta} \chi^{\Delta \Delta}(s)\right) \Delta s=\infty
$$

and

$$
\int_{\mathrm{t}_{0}}^{\mathrm{t}} \mathrm{a}(\mathrm{s})\left(\mathrm{x}^{\Delta \Delta}(\mathrm{s})\right)^{2} \Delta \mathrm{s}=\infty .
$$

Proof. Assume that $x(t)$ be a solution of (1.2) belongs to class $S_{I I}$. By Theorem 3.7 we see that, either $x(t)$ is oscillatory or $\lim _{t \rightarrow \infty} x(t)=0$. Assume that $x(t)$ is oscillatory and choose $T \geqslant t_{0}$ large enough so that $F[x(t)]<0$. Then by Lemma 3.2, we see that $F[x(t)]<0$ for $t \geqslant T$. Define

$$
J[x(t)]=a(t) x(t) x^{\Delta}(t)-\int_{T}^{t} a^{\Delta}(s) x(s) x^{\Delta}(s) \Delta s-2 \int_{T}^{t} a^{\sigma}(s)\left(\chi^{\Delta}(s)\right)^{2} \Delta s-\int_{T}^{t} \mu(s)[a(s) x(s)]^{\Delta} \chi^{\Delta \Delta}(s) \Delta s,
$$

for $t \geqslant T \geqslant t_{0}$. Then

$$
\begin{aligned}
& \mathrm{J}^{\Delta}[\mathrm{x}(\mathrm{t})]=\mathrm{a}^{\Delta}(\mathrm{t}) \mathrm{x}(\mathrm{t}) \mathrm{x}^{\Delta}(\mathrm{t})+\mathrm{a}^{\sigma}(\mathrm{t}) \mathrm{x}^{\sigma}(\mathrm{t}) \mathrm{x}^{\Delta \Delta}(\mathrm{t})+\mathrm{a}^{\sigma}(\mathrm{t})\left(\mathrm{x}^{\Delta}(\mathrm{t})\right)^{2}-\mathrm{a}^{\Delta}(\mathrm{t}) \mathrm{x}(\mathrm{t}) \mathrm{x}^{\Delta}(\mathrm{t})-2 \mathrm{a}^{\sigma}(\mathrm{t})\left(\mathrm{x}^{\Delta}(\mathrm{t})\right)^{2} \\
& -\mu(\mathrm{t}) a^{\sigma}(\mathrm{t}) x^{\Delta}(\mathrm{t}) x^{\Delta \Delta}(\mathrm{t})-\mu(\mathrm{t}) a^{\Delta}(\mathrm{t}) x(\mathrm{t}) x^{\Delta \Delta}(\mathrm{t}) \\
& =\mathrm{a}^{\sigma}(\mathrm{t}) \mathrm{x}^{\sigma}(\mathrm{t}) \mathrm{x}^{\Delta \Delta}(\mathrm{t})-\mathrm{a}^{\sigma}(\mathrm{t})\left(\mathrm{x}^{\Delta}(\mathrm{t})\right)^{2}-\mu(\mathrm{t}) \mathrm{a}^{\sigma}(\mathrm{t}) \mathrm{x}^{\Delta}(\mathrm{t}) \mathrm{x}^{\Delta \Delta}(\mathrm{t})-\mu(\mathrm{t}) \mathrm{a}^{\Delta}(\mathrm{t}) x(\mathrm{t}) \mathrm{x}^{\Delta \Delta}(\mathrm{t}) \\
& =\left(x^{\sigma}(\mathrm{t})-\mu(\mathrm{t}) \mathrm{x}^{\Delta}(\mathrm{t})\right) \mathrm{a}^{\sigma}(\mathrm{t}) \mathrm{x}^{\Delta \Delta}(\mathrm{t})-\mathrm{a}^{\sigma}(\mathrm{t})\left(\mathrm{x}^{\Delta}(\mathrm{t})\right)^{2}-\mu(\mathrm{t}) \mathrm{a}^{\Delta}(\mathrm{t}) \mathrm{x}(\mathrm{t}) \mathrm{x}^{\Delta \Delta}(\mathrm{t}) \\
& =a^{\sigma}(\mathrm{t}) x(\mathrm{t}) \mathrm{x}^{\Delta \Delta}(\mathrm{t})-\mu(\mathrm{t}) \mathrm{a}^{\Delta}(\mathrm{t}) x(\mathrm{t}) \mathrm{x}^{\Delta \Delta}(\mathrm{t})-\mathrm{a}^{\sigma}(\mathrm{t})\left(\mathrm{x}^{\Delta}(\mathrm{t})\right)^{2} \\
& =a(t) x(t) x^{\Delta \Delta}(t)-a^{\sigma}(t)\left(x^{\Delta}(t)\right)^{2} \text {. }
\end{aligned}
$$

From (iii), we get for all $t \geqslant T$ that

$$
\mathrm{J}^{\Delta}[x(\mathrm{t})] \leqslant \mathrm{a}(\mathrm{t}) x(\mathrm{t}) \mathrm{x}^{\Delta \Delta}(\mathrm{t})-\mathrm{a}(\mathrm{t})\left(\mathrm{x}^{\Delta}(\mathrm{t})\right)^{2}=\mathrm{F}[\mathrm{x}(\mathrm{t})]-\mathrm{p}(\mathrm{t}) \mathrm{x}^{2}(\mathrm{t})-\frac{1}{2} \mathrm{a}(\mathrm{t})\left(\mathrm{x}^{\Delta}(\mathrm{t})\right)^{2} \leqslant \mathrm{~F}[\mathrm{x}(\mathrm{t})]<0 .
$$

Integrating from $T$ to $t$, we obtain

$$
\mathrm{J}_{\mathrm{T}}[\mathrm{t}] \leqslant \mathrm{J}_{\mathrm{T}}[\mathrm{T}]+\mathrm{F}[\mathrm{x}(\mathrm{t})](\mathrm{t}-\mathrm{T}) \rightarrow-\infty, \quad \text { as } \mathrm{t} \rightarrow \infty .
$$

That is,

$$
\begin{aligned}
& {\left[\operatorname { l i m } _ { t \rightarrow \infty } \left(a(t) x(t) x^{\Delta}(t)-\int_{T}^{t} a^{\Delta}(s) x(s) x^{\Delta}(s) \Delta s-2 \int_{T}^{t} a^{\sigma}(s)\left(x^{\Delta}(s)\right)^{2} \Delta s\right.\right.} \\
& \left.-\int_{T}^{t} \mu(s)[a(s) x(s)]^{\Delta} x^{\Delta \Delta}(s) \Delta s\right)=-\infty .
\end{aligned}
$$

If

$$
\int_{T}^{t}\left(a^{\sigma}(s)\left(x^{\Delta}(s)\right)^{2}+\frac{1}{2} \mu(s)[a(s) x(s)]^{\Delta} x^{\Delta \Delta}(s)\right) \Delta s<\infty,
$$

then we assume that there is a sequence $\left\{t_{n}\right\}$ of zeros of $x(t)$, such that

$$
-\int_{\mathrm{T}}^{\mathrm{t}_{\mathrm{n}}} \mathrm{a}^{\Delta}(\mathrm{s}) \chi(\mathrm{s}) \mathrm{x}^{\Delta}(\mathrm{s}) \Delta \mathrm{s} \rightarrow-\infty, \quad \text { as } \mathrm{n} \rightarrow \infty .
$$

By using $\left(\mathrm{H}_{4}\right)$, we get

$$
-\int_{T}^{t_{n}} a^{\Delta}(s) x(s) x^{\Delta}(s) \Delta s \leqslant \frac{\alpha}{2} \int_{T}^{t}\left[(x(s))^{2}+\left(x^{\Delta}(s)\right)^{2}\right] \Delta s<\infty,
$$


which contradicts (3.15). Now assume that $\lim _{t \rightarrow \infty} x(t)=0$. Since $x(t)$ is oscillatory, it is clear that $x(t) x^{\Delta}(t) \leqslant 0$, for $t \geqslant T_{1}$ for some $T_{1} \geqslant t_{0}$. This implies $\left(-a^{\Delta}(t) x(t) x^{\Delta}(t)\right) \geqslant 0$, so by (3.14),

$$
\lim _{t \rightarrow \infty} a(t) x(t) x^{\Delta}(t)-2 \int_{T}^{t} a^{\sigma}(s)\left(\chi^{\Delta}(s)\right)^{2} \Delta s-\int_{T}^{t} \mu(s)[a(s) x(s)]^{\Delta} \chi^{\Delta \Delta}(s) \Delta s=-\infty .
$$

Again if

$$
-\int_{T}^{t}\left(a^{\sigma}(s)\left(x^{\Delta}(s)\right)^{2}+\frac{1}{2} \mu(s)[a(s) x(s)]^{\Delta} \chi^{\Delta \Delta}(s)\right) \Delta s<\infty
$$

then

$$
\lim _{t \rightarrow \infty} a(t) x(t) x^{\Delta}(t)=-\infty
$$

and hence,

$$
a(t) x(t) x^{\Delta}(t) \leqslant-D<0, \text { for } t \geqslant T_{2},
$$

for some positive constant $D$ and some $T_{2} \geqslant T_{1}$. Thus, $x(t) x^{\Delta}(t) \leqslant-D / a(t)$ for $t \geqslant T_{2}$. An integration gives us that

$$
\int_{T_{2}}^{t} x(s) x^{\Delta}(s) \Delta s \leqslant-D \int_{T_{2}}^{t} \frac{1}{a(s)} \Delta s
$$

then

$$
\frac{1}{2} \int_{\mathrm{T}_{2}}^{\mathrm{t}}\left[x(\mathrm{~s})+\left(\chi^{\sigma}(\mathrm{s})-\mu(\mathrm{s}) \chi^{\Delta}(\mathrm{s})\right)\right] x^{\Delta}(\mathrm{s}) \Delta \mathrm{s} \leqslant-\mathrm{D} \int_{\mathrm{T}_{2}}^{\mathrm{t}} \frac{1}{\mathrm{a}(\mathrm{s})} \Delta \mathrm{s},
$$

which implies that

$$
\frac{1}{2} \int_{\mathrm{T}_{2}}^{\mathrm{t}}\left(\chi(\mathrm{s})+\chi^{\sigma}(\mathrm{s})\right) \chi^{\Delta}(\mathrm{s}) \Delta \mathrm{s}-\frac{1}{2} \int_{\mathrm{T}_{2}}^{\mathrm{t}} \mu(\mathrm{s})\left(\chi^{\Delta}(\mathrm{s})\right)^{2} \Delta \mathrm{s} \leqslant-\mathrm{D} \int_{\mathrm{T}_{2}}^{\mathrm{t}} \frac{1}{\mathrm{a}(\mathrm{s})} \Delta \mathrm{s} .
$$

Integrating by parts, we obtain as $t \rightarrow \infty$, that

$$
\frac{1}{2}\left[x^{2}(t)-\chi^{2}\left(T_{2}\right)\right] \leqslant-D \int_{T_{2}}^{t} \frac{1}{a(s)} \Delta s+\frac{1}{2} \int_{T_{2}}^{t} \mu(s)\left(x^{\Delta}(s)\right)^{2} \Delta s \rightarrow-\infty,
$$

which contradicts $x(t) \rightarrow 0$ as $t \rightarrow \infty$. Therefore, (3.12) of the theorem holds. To prove (3.13), we assume that $x(t)$ is a solution of (1.2) belonging to class $S_{I I}$ and $T \geqslant t_{0}$ be chosen so that $F[x(t)]<0$ for $t \geqslant T$. Multiplying (1.2) by $x^{\Delta}(\sigma(t))$ and integrating from $T$ to $t$, we obtain

$$
\begin{aligned}
& \int_{T}^{t}\left[\mathrm{a}(\mathrm{s}) \mathrm{x}^{\Delta \Delta}(\mathrm{s})+\mathrm{p}(\mathrm{s}) \chi(\mathrm{s})\right]^{\Delta} \chi^{\Delta}(\sigma(\mathrm{s})) \Delta \mathrm{s} \\
& \quad+\int_{\mathrm{T}}^{\mathrm{t}} \mathrm{p}(\mathrm{s}) \mathrm{x}^{\Delta}(\mathrm{s}) \mathrm{x}^{\Delta}(\sigma(\mathrm{s})) \Delta \mathrm{s}+\int_{\mathrm{T}}^{\mathrm{t}} \mathrm{q}(\mathrm{s}) \chi^{\Delta}(\sigma(\mathrm{s})) \mathrm{f}\left(\chi^{\sigma}(\mathrm{s})\right) \Delta \mathrm{s}=0 .
\end{aligned}
$$

Integrating by parts, we get that

$$
\begin{aligned}
& a(t) x^{\Delta \Delta}(\mathrm{t}) x^{\Delta}(\mathrm{t})+\mathrm{p}(\mathrm{t}) x(\mathrm{t}) x^{\Delta}(\mathrm{t})-\mathrm{a}(\mathrm{T}) \mathrm{x}^{\Delta \Delta}(\mathrm{T}) \mathrm{x}^{\Delta}(\mathrm{T}) \\
& -\mathrm{p}(\mathrm{T}) x(\mathrm{~T}) \mathrm{x}^{\Delta}(\mathrm{T})-\int_{\mathrm{T}}^{\mathrm{t}}\left[\mathrm{a}(\mathrm{s}) \mathrm{x}^{\Delta \Delta}(\mathrm{s})+\mathrm{p}(\mathrm{s}) x(\mathrm{~s})\right] x^{\Delta \Delta}(\mathrm{s}) \Delta \mathrm{s} \\
& +\int_{T}^{\mathrm{t}} \mathrm{p}(\mathrm{s}) \mathrm{x}^{\Delta}(\mathrm{s}) x^{\Delta}(\sigma(\mathrm{s})) \Delta \mathrm{s}+\int_{\mathrm{T}}^{\mathrm{t}} \mathrm{q}(\mathrm{s}) \mathrm{x}^{\Delta}(\sigma(\mathrm{s})) \mathrm{f}\left(\mathrm{x}^{\sigma}(\mathrm{s})\right) \Delta \mathrm{s}=0 .
\end{aligned}
$$

Now, we define

$$
G(t)=-a(t) x^{\Delta \Delta}(t) x^{\Delta}(t)-p(t) x(t) x^{\Delta}(t)
$$


and

$$
\mathrm{C}_{0}=\mathrm{a}(\mathrm{T}) \mathrm{x}^{\Delta \Delta}(\mathrm{T}) \mathrm{x}^{\Delta}(\mathrm{T})+\mathrm{p}(\mathrm{T}) x(\mathrm{~T}) \mathrm{x}^{\Delta}(\mathrm{T}) .
$$

From (3.16), (3.17), and (3.18), we obtain that

$$
\begin{aligned}
& \mathrm{C}_{0}-\int_{\mathrm{T}}^{\mathrm{t}} \mathrm{q}(\mathrm{s}) \mathrm{x}^{\Delta}(\sigma(\mathrm{s})) \mathrm{f}\left(\mathrm{x}^{\sigma}(\mathrm{s})\right) \Delta \mathrm{s}+\mathrm{G}(\mathrm{t})+\int_{\mathrm{T}}^{\mathrm{t}} \mathrm{a}(\mathrm{s})\left(\chi^{\Delta \Delta}(\mathrm{s})\right)^{2} \Delta \mathrm{s} \\
& =\int_{T}^{t} p(s) x^{\Delta}(s) x^{\Delta}(\sigma(s)) \Delta s-\int_{T}^{t} p(s) x(s) x^{\Delta \Delta}(s) \Delta s \\
& =\frac{1}{2} \int_{T}^{t} p(s)\left(x^{\Delta}(s)\right)^{2}+\int_{T}^{t} \mu(s) p(s) x^{\Delta}(s) x^{\Delta \Delta}(s) \Delta s-\int_{T}^{t} p(s)\left(x(s) x^{\Delta \Delta}(s)-\frac{1}{2}\left(x^{\Delta}(s)\right)^{2}\right) \Delta s \\
& \geqslant \frac{1}{2} \int_{T}^{t} p(s)\left(x^{\Delta}(s)\right)^{2}+\int_{T}^{t} \mu(s) p(s) x^{\Delta}(s) x^{\Delta \Delta}(s) \Delta s \text {. }
\end{aligned}
$$

Furthermore,

$$
-\int_{T}^{t} q(s) x^{\Delta}(\sigma(s)) f\left(x^{\sigma}(s)\right) \Delta s=-q(t) H(x(t))+\int_{T}^{t} q^{\Delta}(s) H(x(s)) \Delta s+C_{1}
$$

where

$$
H(x)=\int_{0}^{x} f(u) d u \geqslant 0
$$

and $C_{1}=q(T) H(x(T))$. Since $q^{\Delta}(t) \leqslant 0$, we get

$$
\mathrm{C}_{0}+\mathrm{C}_{1}+\mathrm{G}(\mathrm{t})+\int_{\mathrm{T}}^{\mathrm{t}} \mathrm{a}(\mathrm{s})\left(x^{\Delta \Delta}(\mathrm{s})\right)^{2} \Delta \mathrm{s} \geqslant \frac{1}{2} \int_{T}^{\mathrm{t}} \mathrm{p}(\mathrm{s})\left(x^{\Delta}(\mathrm{s})\right)^{2}+\int_{\mathrm{T}}^{\mathrm{t}} \mu(\mathrm{s}) \mathrm{p}(\mathrm{s}) \mathrm{x}^{\Delta}(\mathrm{s}) \mathrm{x}^{\Delta \Delta}(\mathrm{s}) \Delta \mathrm{s},
$$

that is,

$$
\mathrm{C}_{0}+\mathrm{C}_{1}+\mathrm{G}(\mathrm{t})+\int_{\mathrm{T}}^{\mathrm{t}} \mathrm{a}(\mathrm{s})\left(\mathrm{x}^{\Delta \Delta}(\mathrm{s})\right)^{2} \Delta \mathrm{s} \geqslant \frac{\sigma}{2} \int_{\mathrm{T}}^{\mathrm{t}}\left[\left(x^{\Delta}(\mathrm{s})\right)^{2}+\mu(\mathrm{s}) \mathrm{x}^{\Delta}(\mathrm{s}) x^{\Delta \Delta}(\mathrm{s})\right] \Delta \mathrm{s} .
$$

By Theorem 3.7, either $x(t)$ oscillates or $x(t) \rightarrow 0$ as $t \rightarrow \infty$. Assume that

$$
\int_{t_{0}}^{t} a(s)\left(x^{\Delta \Delta}(s)\right)^{2} \Delta s<\infty
$$

If $x(t)$ is oscillatory, then $x^{\Delta}(t)$ is oscillatory and assume that there exists an increasing sequence $\left\{t_{n}\right\}$ of zeros of $x^{\Delta}(t)$. In view of (3.19), we must have $G(t) \rightarrow \infty$ as $t \rightarrow \infty$. However, $G\left(t_{n}\right)=0$ for $t=t_{n}$, $\mathrm{n}=1,2,3, \ldots$, which contradicts the divergence $\mathrm{G}(\mathrm{t}) \rightarrow \infty$ as $\mathrm{t} \rightarrow \infty$. If $x(\mathrm{t}) \rightarrow 0$ as $\mathrm{t} \rightarrow \infty$, then there exists $\epsilon>0$ such that $|x(t)| \leqslant \epsilon$ for large $t$, say, for $t \geqslant T_{1}$ for some $T_{1} \geqslant T$. Since $G(t) \rightarrow \infty$ as $t \rightarrow \infty$, there exists

$$
L<-a(t) x^{\Delta \Delta}(t) x^{\Delta}(t)-p(t) x(t) x^{\Delta}(t), \text { for } t \geqslant T_{2} .
$$

Integrating, we obtain

$$
\begin{aligned}
\mathrm{L}\left(\mathrm{t}-\mathrm{T}_{2}\right)< & -\int_{\mathrm{T}_{2}}^{\mathrm{t}} \mathrm{a}(\mathrm{s}) \mathrm{x}^{\Delta \Delta}(\mathrm{s}) x^{\Delta}(\mathrm{s}) \Delta \mathrm{s}-\int_{\mathrm{T}_{2}}^{\mathrm{t}} \mathrm{p}(\mathrm{s}) x(\mathrm{~s}) \mathrm{x}^{\Delta}(\mathrm{s}) \Delta \mathrm{s} \\
\leqslant & -\frac{1}{2} \mathrm{a}(\mathrm{t})\left(x^{\Delta}(\mathrm{t})\right)^{2}+\frac{1}{2} \int_{\mathrm{T}_{2}}^{\mathrm{t}} \mathrm{a}^{\Delta}(\mathrm{s})\left(\chi^{\Delta}(\sigma(\mathrm{s}))\right)^{2} \Delta s+\frac{1}{2} \int_{\mathrm{T}_{2}}^{\mathrm{t}} \mathrm{a}(\mathrm{s}) \mu(\mathrm{s})\left(x^{\Delta \Delta}(\mathrm{s})\right)^{2} \Delta s-\frac{1}{2} \mathrm{p}(\mathrm{t}) \chi^{2}(\mathrm{t}) \\
& +\frac{1}{2} \int_{\mathrm{T}_{2}}^{\mathrm{t}} \mathrm{p}^{\Delta}(\mathrm{s})(x(\sigma(\mathrm{s})))^{2} \Delta \mathrm{s}+\frac{1}{2} \int_{\mathrm{T}_{2}}^{\mathrm{t}} \mathrm{p}(\mathrm{s}) \mu(\mathrm{s})\left(x^{\Delta}(\mathrm{s})\right)^{2} \Delta s+\mathrm{C}_{3}
\end{aligned}
$$




$$
\begin{aligned}
\leqslant & \frac{1}{2} \int_{\mathrm{T}_{2}}^{\mathrm{t}}\left[\mathrm{a}^{\Delta}(\mathrm{s})\left(\mathrm{x}^{\Delta}(\sigma(\mathrm{s}))\right)^{2} \Delta \mathrm{s}+\mathrm{p}(\mathrm{s}) \mu(\mathrm{s})\left(\mathrm{x}^{\Delta}(\mathrm{s})\right)^{2}\right] \Delta s \\
& +\frac{1}{2} \int_{\mathrm{T}_{2}}^{\mathrm{t}} \mathrm{a}(\mathrm{s}) \mu(\mathrm{s})\left(\mathrm{x}^{\Delta \Delta}(\mathrm{s})\right)^{2} \Delta \mathrm{s}+\frac{\delta \epsilon^{2}}{2}\left(\mathrm{t}-\mathrm{T}_{2}\right)+\mathrm{C}_{3},
\end{aligned}
$$

where

$$
C_{3}=\frac{1}{2} a\left(T_{2}\right)\left(x^{\Delta}\left(T_{2}\right)\right)^{2}+\frac{1}{2} p\left(T_{2}\right) x^{2}\left(T_{2}\right)
$$

Hence

$$
\left(\mathrm{L}-\frac{\delta \epsilon^{2}}{2}\right)\left(\mathrm{t}-\mathrm{T}_{2}\right) \leqslant \frac{1}{2} \int_{\mathrm{T}_{2}}^{\mathrm{t}}\left[\mathrm{a}^{\Delta}(\mathrm{s})\left(\mathrm{x}^{\Delta}(\sigma(\mathrm{s}))\right)^{2} \Delta \mathrm{s}+\mathrm{p}(\mathrm{s}) \mu(\mathrm{s})\left(\mathrm{x}^{\Delta}(\mathrm{s})\right)^{2}+\mathrm{a}(\mathrm{s}) \mu(\mathrm{s})\left(\mathrm{x}^{\Delta \Delta}(\mathrm{s})\right)^{2}\right] \Delta s+\mathrm{C}_{3} .
$$

This implies

$$
\frac{1}{2} \int_{\mathrm{T}_{2}}^{t}\left[\mathrm{a}^{\Delta}(\mathrm{s})\left(\mathrm{x}^{\Delta}(\sigma(\mathrm{s}))\right)^{2} \Delta \mathrm{s}+\mathrm{p}(\mathrm{s}) \mu(\mathrm{s})\left(\mathrm{x}^{\Delta}(\mathrm{s})\right)^{2}+\mathrm{a}(\mathrm{s}) \mu(\mathrm{s})\left(\mathrm{x}^{\Delta \Delta}(\mathrm{s})\right)^{2}\right] \Delta \mathrm{s} \rightarrow \infty,
$$

as $t \rightarrow \infty$. By Remark 3.9, we get

$$
\int_{\mathrm{T}_{2}}^{t}\left(x^{\sigma}(s)\right)^{2} \Delta s<\infty, \int_{\mathrm{T}_{2}}^{t}\left(x^{\Delta}(s)\right)^{2} \Delta s<\infty, \text { and } \int_{\mathrm{T}_{2}}^{\mathrm{t}}\left(x^{\Delta \Delta}(\mathrm{s})\right)^{2} \Delta s<\infty .
$$

Thus from (3.20) and (3.21), we see that

$$
\left(L-\frac{\delta \epsilon^{2}}{2}\right) t<C_{3}+L T_{2}, \text { for } t \geqslant T_{2}
$$

which is impossible. This contradiction shows that part (3.13) holds and the proof is complete.

\section{References}

[1] R. P. Agarwal, M. Bohner, T. X. Li, C. H. Zhang, Hille and Nehari type criteria for third-order delay dynamic equations, J. Difference Equ. Appl., 19 (2013), 1563-1579. 1

[2] R. P. Agarwal, M. Bohner T. X. Li, C. H. Zhang, Oscillation of third-order nonlinear delay differential equations, Taiwanese J. Math., 17 (2013), 545-558. 1

[3] R. P. Agarwal, M. Bohner, T. X. Li, C. H. Zhang, A Philos-type theorem for third-order nonlinear retarded dynamic equations, Appl. Math. Comput., 249 (2014), 527-531. 1

[4] R. P. Agarwal, M. Bohner D. O’Regan, A. Peterson, Dynamic equations on time scales: A survey, J. Comput. Appl. Math., 141 (2002), 1-26. 1

[5] R. P. Agarwal, M. Bohner, S. H. Saker, Oscillation of second order delay dynamic equations, Can. Appl. Math. Q., 13 (2005), 1-19. 1

[6] R. P. Agarwal, M. Bohner, S. H. Tang, T. X. Li, C. H. Zhang, Oscillation and asymptotic behavior of third-order nonlinear retarded dynamic equations, Appl. Math. Comput., 219 (2012), 3600-3609. 1

[7] R. P. Agarwal, D. O’Regan, S. H. Saker, Oscillation criteria for second-order nonlinear neutral delay dynamic equations, J. Math. Anal. Appl., 300 (2004), 203-217. 1

[8] E. Akin-Bohner, M. Bohner, S. H. Saker, Oscillation criteria for a certain class of second order Emden-Fowler dynamic Equations, Electron. Trans. Numer. Anal., 27 (2007), 1-12. 1

[9] M. Bohner, A. Peterson, Dynamic Equations on Time Scales, An Introduction with Applications, Birkhäuser, Boston, (2001). 1, 2

[10] M. Bohner, A. Peterson, Advances in dynamics equations on time scales, Birkhäuser, Boston, (2003). 1

[11] M. Bohner, S. H. Saker, Oscillation of second order nonlinear dynamic equations on time scales, Rocky Mountain J. Math., 34 (2004), 1239-1254. 1

[12] M. Bohner, S. H. Saker, Oscillation criteria for perturbed nonlinear dynamic equations, Math. Comput. Modelling, 40 (2004), 249-260. 1

[13] G. E. Chatzarakis, S. R. Grace, I. Jadlovsk, T. Li, E. Tunç, Oscillation criteria for third-order Emden-Fowler differential equations with unbounded neutral coefficients, Complexity, 2019 (2019), 1-7. 1 
[14] L. Erbe, A. Peterson, S. H. Saker, Asymptotic behavior of solutions of a third-order nonlinear dynamic equation on time scales, J. Comput. Appl. Math., 181 (2005), 92-102. 1

[15] L. Erbe, A. Peterson, S. H. Saker, Oscillation and asymptotic behavior of a third-order nonlinear dynamic equation, Can. Appl. Math. Q., 14 (2006), 129-147. 1

[16] L. Erbe, A. Peterson, S. H. Saker, Hille and Nehari type criteria for third order dynamic equations, J. Math. Anal. Appl., 329 (2007), 112-131. 1

[17] S. Frassu, C. van der Mee, G. Viglialoro, Boundedness in a nonlinear attraction-repulsion Keller-Segel system with production and consumption, J. Math. Anal. Appl., 504 (2021), 20 pages. 1

[18] S. Frassu, G. Viglialoro, Boundedness for a fully parabolic Keller-Segel model with sublinear segregation and superlinear aggregation, Acta Appl. Math., 171 (2021), 20 pages. 1

[19] S. R. Grace, J. R. Graef, M. A. El-Beltagy, On the oscillation of third order delay dynamic equations on time scales, Comput. Math. Appl., 63 (2012), 775-782. 1, 1

[20] J. R. Greaf, M. Remili, Qualitative behavior of solutions of a third order nonlinear differential equation, Math. Nachr., 209 (2017), 2832-2844. 1, 3.6

[21] S. Hilger, Analysis on measure chains-A unified approach to continuous and discrete calculus, Result Math., 18 (1990), 18-56. 1

[22] V. Kac, P. Cheung, Quantum Calculus, Springer-Verlag, New York, (2001). 1

[23] T. X. Li, Z. L. Han, S. R. Sun, Y. G. Zhao, Oscillation results for third order nonlinear delay dynamic equations on time scales, Bull. Malays. Math. Sci. Soc. (2), 34 (2011), 639-648. 1

[24] T. X. Li, Y. V. Rogovchenko, On the asymptotic behavior of solutions to a class of third-order nonlinear neutral differential equations, Appl. Math. Lett., 105 (2020), 7 pages. 1

[25] T. Li, G. Viglialoro, Boundedness for a nonlocal reaction chemotaxis model even in the attraction dominated regime, Differ. Integ. Equ., 34 (2021), 315-336. 1

[26] M. Morelli, A. Peterson, A third-order differential equation on a time scale, Math. Comput. Modelling, 32 (2000), 565-570. 1

[27] S. H. Saker, Oscillation Theory of Dynamic Equations on Time Scales: Second and Third Orders, Lambert Academic Publishing, Berlin, (2010). 1

[28] S. H. Saker, J. Greaf, Oscillation of third-order nonlinear neutral functional dynamic equations on time scales, Dynam. Systems Appl., 21 (2012), 583-606. 1, 1

[29] M. T. Senel, N. Utku, Oscillation behavior of third-order nonlinear neutral dynamic equations on time scales with distributed deviating arguments, Filomat, 28 (2014), 1211-1223. 1

[30] Z.-H. Yu, Q.-R. Wang, Asymptotic behavior of solutions of third order nonlinear dynamic equations on time scales, J. Comput. Appl. Math., 225 (2009), 531-540. 1, 1 